\title{
Short Communication: Comparison of Manual Versus Semiautomatic Milk Recording Systems in Dairy Goats
}

\author{
A. Ait-Saidi, ${ }^{*}$ G. Caja, ${ }^{* 1}$ S. Carné, ${ }^{*}$ A. A. K. Salama, ${ }^{*} \dagger$ and J. J. Ghirardi ${ }^{* 2}$ \\ *Grup de Recerca en Remugants, Departament de Ciència Animal i dels Aliments, Universitat Autònoma de Barcelona, Bellaterra, Spain \\ †Sheep and Goat Research Department, Animal Production Research Institute, 12311 Dokki, Giza, Egypt
}

\begin{abstract}
A total of 24 Murciano-Granadina dairy goats in early-midlactation were used to compare the labor time and data collection efficiency of using manual (M) vs. semiautomated (SA) systems for milk recording. Goats were milked once daily in a $2 \times 12$ parallel platform, with 6 milking units on each side. The $\mathrm{M}$ system used visual identification (ID) by large plastic ear tags, onpaper data recording, and data manually uploaded to a computer. The SA system used electronic ID, automatic ID, manual data recording on reader keyboard, and automatic data uploading to computer by Bluetooth connection. Data were collected for groups of $2 \times 12$ goats for 15 test days of each system during a period of $70 \mathrm{~d}$. Time data were converted to a decimal scale. No difference in milk recording time between $\mathrm{M}$ and $\mathrm{SA}(1.32 \pm 0.03$ and $1.34 \pm 0.03 \mathrm{~min} /$ goat, respectively) was observed. Time needed for transferring data to the computer was greater for $\mathrm{M}$ when compared with SA $(0.20 \pm 0.01$ and $0.05 \pm 0.01 \mathrm{~min} /$ goat $)$. Overall milk recording time was greater in $\mathrm{M}$ than in SA (1.52 \pm 0.04 vs. $1.39 \pm 0.04 \mathrm{~min} /$ goat), the latter decreasing with operator training. Time for transferring milk recording data to the computer was $4.81 \pm 0.34$ and $1.09 \pm 0.10$ min for M and SA groups of 24 goats, respectively, but only increased by $0.19 \mathrm{~min}$ in SA for each additional 24 goats. No difference in errors of data acquisition was detected between $\mathrm{M}$ and SA systems during milk recording $(0.6 \%)$, but an additional $1.1 \%$ error was found in the $\mathrm{M}$ system during data uploading. Predicted differences between $M$ and SA increased with the number of goats processed on the test-day. Reduction in labor time cost ranged from $€ 0.5$ to 12.9 (US $\$ 0.7$ to 17.4) per milk recording, according to number of goats from 24 to 480 goats and accounted for $40 \%$ of the electronic ID costs. In conclusion, electronic ID was
\end{abstract}

Received October 31, 2007.

Accepted December 12, 2007.

${ }^{1}$ Corresponding author: gerardo.caja@uab.es

${ }^{2}$ Current address: Rumitag S.L., Esmergarda 19-21 Sobreàtic, 08950 Esplugues de Llobregat, Spain. more efficient for labor costs and resulted in fewer data errors, the benefit being greater with trained operators and larger goat herds.

Key words: dairy goat, electronic identification, milk recording, transponder

Automation of milk recording in dairy small ruminants may be a way of reducing costs and human errors (Ricard et al., 1994; Ilahi et al., 1999) due to the large number of animals processed on the test-days. Although automatic equipment is available on the market (Afimilk, 2007; DeLaval, 2007; WestfaliaSurge, 2007), in practice few commercial goat farms have implemented automated milk recording systems. The main drawback for farmers is the high acquisition cost of the equipment required for automatic goat identification (ID) and for the recording of milk volume or milk flow.

Electronic identification (e-ID) of goats, using glassencapsulated transponders subcutaneously injected in the armpit jointly with manual milk recording, was initially used for milk recording in Spain (Caja et al., 1999). Milk recording time and data processing errors were lower when compared with visual ID and manual milk recording. In the frame of European Union (EU) Regulation 21/2004 on sheep and goat ID and registration, injectable transponders were substituted by electronic boluses by the Spanish legislation (Real Decreto 947/2005). An electronic bolus is a capsule containing a transponder that is orally administered and retained in the reticulorumen (Fallon, 2001; Ghirardi et al., $2006 a, b)$. Bolus retention rate in goats may vary according to bolus design (Ghirardi et al., 2006a,b; Carné et al., 2007), but goat ID by boluses using ISO (International Organization for Standardization) transponders (ISO, 1996) was efficient under practical farming conditions (Pinna et al., 2006; JRC, 2007).

The objective of this study was to evaluate the impact of using e-ID in a semiautomated (SA) system for milk recording of dairy goats on labor time and data collection efficiency when compared with the conventional system based on visual ID and manual (M) data collection. 
Animal care conditions and management practices followed procedures stated by the Ethical Committee of Animal and Human Experimentation of the Universitat Autonoma de Barcelona (UAB) and codes of recommendations for the welfare of livestock of the Ministry of Agriculture, Fisheries and Food of Spain (MAPA, 2007).

A total of 24 multiparous Murciano-Granadina dairy goats, located on the experimental farm of the S1GCE (Servei de Granges i Camps Experimentals) of the UAB in Bellaterra (Barcelona, Spain), were used. Goats were milked once daily throughout lactation according to Salama et al. (2003). Milking was at $0900 \mathrm{~h}$ in a double12 stall case system parallel milking parlor (WestfaliaSurge Ibérica, Granollers, Spain) equipped with a low milk pipeline, 6 milking units on each side, recording jars, and automatic head lockers. Milking routine, to which the goats were adapted in previous lactations, included machine milking (cluster attachment without udder preparation), machine stripping, cluster removal, and teat disinfection by dipping (P3-cide plus, Henkel Hygiene, Barcelona, Spain). Goats grazed Italian ryegrass for $6 \mathrm{~h} / \mathrm{d}$ and were supplemented with 0.5 $\mathrm{kg} / \mathrm{d}$ of alfalfa pellets in the shelter, and with 0.5 to 1.0 $\mathrm{kg} / \mathrm{d}$ of a commercial concentrate $\left(1.53 \mathrm{Mcal}\right.$ of $\mathrm{NE}_{\mathrm{L}} /$ $\mathrm{kg} ; 16 \% \mathrm{CP}$, as fed) according to lactation stage in the milking parlor. The experimental period was initiated when the goats were in early-middle lactation (60 to 120 DIM) and consisted of 15 milk recording test-days in 24 goats for each treatment during $70 \mathrm{~d}$ (720 milk recording data). Milk recording data were collected at random by $\mathrm{M}$ or SA methods by parlor side and in groups of 12 random goats.

Goats were identified in the right ear with a plastic round button ear tag (Azasa-Allflex, Madrid, Spain) used for mandatory health programs in Catalonia. Additionally, a second plastic ear tag of a flag type and large size ( $48 \times 38 \mathrm{~mm}$, yellow color; Azasa-Allflex) was inserted in the left ear. These large ear tags were manually marked with 3 digits of $27 \times 10 \mathrm{~mm}$ each (black plastic ink, Allflex Tag Pen, Dallas, TX) for easy reading in the M ID system experimental treatment. At the M milk recording, groups of 12 goats were individually identified by sequential visual reading of the large ear tags (from the front side of the milking parlor platform with the help of the milker) and their numbers recorded in sequential order on paper forms. Time necessary for ID of the 12 goats was recorded by using an electronic chronometer (Geonaute Trt'L 100, Decathlon, Alcobendas, Spain). Milking time, including individual recording of milk yield, but not milk sampling, and observations (i.e., suspected mastitis, cluster fall down), were separately recorded for each 12 -goat group using the same chronometer and paper form. Finally, milk re- cording data were manually uploaded to a computer spreadsheet database.

All goats were e-ID with an electronic bolus (75 g; 21 $\times 68 \mathrm{~mm}$, Rumitag, Barcelona, Spain), which consisted of a high-density ceramic capsule containing an ISO radiofrequency transponder (ISO, 1996) and were used for the SA milk recording treatment. Transponders were of half-duplex technology, glass encapsulated (32 $\times 3.8 \mathrm{~mm}$ ), and marked with a serial code which included the manufacturer code (code 964, Rumitag, $\mathrm{n}=$ 18; code 983, Tiris, Almelo, the Netherlands, $\mathrm{n}=6$ ) according to the International Committee for Animal Recording (ICAR, 2007).

Reading of electronic boluses was done by a handheld intelligent transceiver with internal memory and keyboard (Smart Reader, Rumitag), which could be connected to a 70-cm-long stick antenna (SAS-ISO, Rumitag). A list of equivalences (correspondence between transponder ID code and visual ear tag number) was previously uploaded from a computer to the transceiver memory by means of a Bluetooth connection using the software provided by the manufacturer (Smart software v.3.3.2, Rumitag).

Groups of 12 goats were individually identified by reading their boluses at the time of milk recording by the same operator doing the milk recording. Boluses were read from the rear (milking parlor pit) by positioning the stick antenna of the hand-held transceiver to the left side of the thorax (reticulum) or to the abdomen (ventral rumen sac) of the goat. Milk yield and observation data were typed by the operator on the transceiver keyboard. Data were stored in the memory of the transceiver and automatically uploaded to the computer by using the Bluetooth connection and the same software as above. Milk recording time for the group of 12 goats, including time for ID and recording of milk yield and observations, was recorded by using the chronometer.

Data were analyzed by ANOVA using the PROC GLM (version 9.1; SAS Inst. Inc., Cary, NC). Time measurements were converted to a decimal scale $(1 \mathrm{~min}=100 \mathrm{~s})$ for calculations. The statistical model for milk recording time contained the effects of the milk recording system or treatment (M, SA), the milking recording groups (1 or 2), the test-day (d 1 to 15), the first order interactions, and the residual error. Milk yield of each goat group at the test day was used as covariate. Any factor or interaction term with $P$-value greater than 0.20 was deleted from the model. Comparison of times for $\mathrm{M}$ or SA systems data upload was analyzed for groups of 24 goats performed on the same test day.

Differences between least squares means were separated using the PDIFF test in SAS and declared significant at $P<0.05$. Pearson correlation coefficients were calculated. 
Table 1. Comparison of manual and semiautomated milk recording systems in dairy goats (values are least squares means $\pm \mathrm{SEM}$ )

\begin{tabular}{|c|c|c|c|}
\hline \multirow[b]{2}{*}{ Item } & \multicolumn{2}{|c|}{ System } & \multirow[b]{2}{*}{$P$} \\
\hline & Manual & Semiautomatic & \\
\hline Records, $\mathrm{n}$ & 360 & 360 & - \\
\hline Milk yield per goat, $\mathrm{L} / \mathrm{d}$ & $1.91 \pm 0.04$ & $1.94 \pm 0.04$ & 0.156 \\
\hline Milk rate at recording, $\mathrm{L} / \mathrm{min}$ & $1.45 \pm 0.03$ & $1.46 \pm 0.04$ & 0.539 \\
\hline \multicolumn{4}{|c|}{ Group recording time, $\min / 24$ goat $^{1}$} \\
\hline Milk recording ${ }^{2}$ & $31.45 \pm 0.60$ & $32.16 \pm 0.69$ & 0.505 \\
\hline Data transfer ${ }^{3}$ & $4.81 \pm 0.34$ & $1.09 \pm 0.10$ & 0.001 \\
\hline Overall & $36.26 \pm 0.91$ & $33.25 \pm 0.91$ & 0.011 \\
\hline \multicolumn{4}{|c|}{ Unitary recording time, $\mathrm{min} /$ goat $^{1}$} \\
\hline Milk recording $^{2}$ & $1.32 \pm 0.03$ & $1.34 \pm 0.03$ & 0.511 \\
\hline Data transfer ${ }^{3}$ & $0.20 \pm 0.01$ & $0.05 \pm 0.01$ & 0.001 \\
\hline Overall & $1.52 \pm 0.04$ & $1.39 \pm 0.04$ & 0.002 \\
\hline \multicolumn{4}{|l|}{ Errors, $\mathrm{n}$} \\
\hline Milk recording & $2(0.6 \%)$ & $2(0.6 \%)$ & - \\
\hline Data transfer & $4(1.1 \%)$ & 0 & - \\
\hline
\end{tabular}

${ }^{1}$ Group of 24 goats in a double-12 stall parallel (side by side) milking parlor; time expressed in a decimal scale $(1 \mathrm{~min}=100 \mathrm{~s})$.

${ }^{2}$ Includes goat identification, machine milking, machine stripping, and collecting milk recording data.

${ }^{3}$ From paper forms or intelligent transceiver to computer database.

Individual milk yield during the experiment ranged between 0.33 and $4.10 \mathrm{~L} / \mathrm{d}$, averaging $1.93 \pm 0.04 \mathrm{~L} / \mathrm{d}$ (Table 1). No differences $(P>0.05)$ were detected in milk yield by milk recording system and goat group, but, as a result of stage of lactation, milk yield decreased $(P<0.001)$ throughout the experiment. Monthly coefficient of persistency for milk yield was $91.4 \%$, showing the typical flat lactation curve of Murciano-Granadina dairy goats milked once daily (Salama et al., 2003). Measurement of milk rate at recording did not differ between $\mathrm{M}$ and SA systems, averaging $1.46 \pm 0.04 \mathrm{~L} /$ min (Table 1). Consequently, milk yield or milk flow rates were similar between treatments during the experiment.

Time required for milk recording of each group of 12 goats (including goat ID, machine milking and machine stripping, but excluding goat entrance and exit in the milking parlor and teat disinfection after milking) was $15.90 \pm 0.32$ min during the experiment. There was no difference $(P>0.05)$ in milk recording time between $\mathrm{M}$ and SA treatments, either when expressed per batch of 24 goats ( 2 milking platforms) or as unitary time per goat (Table 1). Although first-order interactions were in general nonsignificant and were deleted from the model, an interaction between milk recording system and milk recording test day $(P=0.029)$ was detected for time required for milk recording.

As shown in Figure 1, milk recording time for group of 12 goats in SA milk recording decreased linearly at a rate of $0.006 \mathrm{~min} / \mathrm{d}\left(\mathrm{R}^{2}=0.40, P<0.001\right)$ when test days progressed during the experiment (15 milk recording events in $70 \mathrm{~d}$ ), indicating that operator skill for using the SA system increased and resulted in sav- ing time for milk recording. This effect was not observed in the $M$ system $\left(\mathrm{R}^{2}=0.03, P>0.05\right)$, showing that no extra training was necessary. At the end of the experimental period (d 70), the estimated times for SA and $M$ were 1.19 and $1.28 \mathrm{~min} /$ goat, respectively, the difference being $0.09 \mathrm{~min} /$ goat ( $6 \mathrm{~s} / \mathrm{goat}$ ) or $2.16 \mathrm{~min} / 24$ goats.

A reduction $(P<0.001)$ in time needed for transferring milk recording data to the computer spreadsheet was observed in favor of SA system for data transfer (Table 1); the reduction of using electronic transfer was $3.72 \mathrm{~min} / 24$ goats or $0.15 \mathrm{~min} /$ goat (9 s/goat) compared with the paper-based M system.

Total transfer time in the $\mathrm{M}$ system linearly increased with number of goats processed at a constant rate of $4.81 \mathrm{~min} / 24$ goats (i.e., 48 goats, $9.62 \mathrm{~min} ; 72$ goats, $14.43 \mathrm{~min})$. The increase was only $0.19 \pm 0.01$ $\mathrm{min} / 24$ goats for the SA system, obtained by measuring the transfer time in 10 simulations of 48 goats from previously collected data.

Registered errors during milk recording were approximately $0.6 \%$ for both milk recording systems, and corresponded to 1 reading and 1 typing error in $\mathrm{M}$, and 2 incorrect automatic readings of goats in SA. Moreover, $1.1 \%$ typing errors were produced in the $\mathrm{M}$ system during data transfer (Table 1).

Finally, overall time needed for milk recording and data transfer jointly was greater $(P<0.05)$ for $\mathrm{M}$ compared with SA system (Table 1), the difference being $3.01 \mathrm{~min} / 24$ goat or $0.13 \mathrm{~min} /$ goat ( $8 \mathrm{~s} /$ goat). This difference increased according to number of goats processed on the same test day for herd sizes of multiples of 24 (2 milking platforms of 12 goats). Billon and Baritaux (1999), and Peris et al. (1999) indicated that a range of 


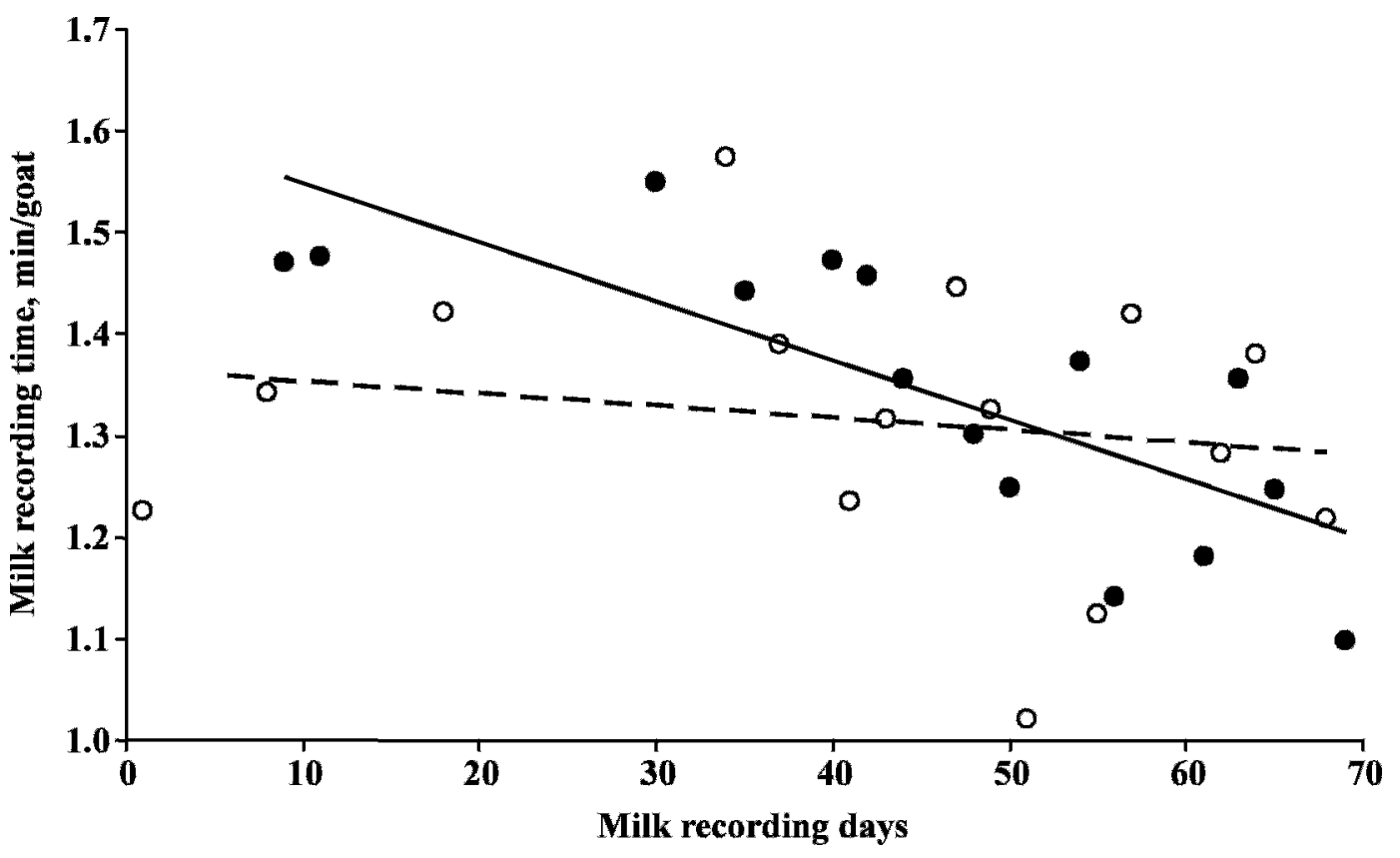

Figure 1. Effect of operator experience for milk recording time when using the manual $(\mathrm{M}, \bigcirc)$ or semiautomatic $(\mathrm{SA}, \bullet)$ milk recording systems in dairy goats. The regression for the SA system (-) was $\mathrm{y}=1.61-0.006 \times\left(\mathrm{R}^{2}=0.40, P<0.001\right)$, but it was nonsignificant for the M system (-- ).

40 to 200 goats/h can be milked in a $2 \times 12$ side-by-side milking parlor (Casse system), depending on milking routine and milking frequency (once or twice daily), which is adequate for medium-size goat herds less than 500 goats.

As a result, for a work wage of $€ 10.0 / \mathrm{h}(\mathrm{US} \$ 13.5 / \mathrm{h})$ or $€ 0.167 / \mathrm{min}(\$ 0.226 / \mathrm{min})$, the use of the SA system would produce a saving in labor cost ranging from $€ 0.5$ to $€ 12.9$ per milk recording ( $\$ 0.68$ to $\$ 17.42$ ) for goat herds from 24 to 480 goats, respectively (conversion rate $1.35 \mathrm{US} \$ / €)$. On the other hand, the SA system saving can only be obtained if all the goats are previously e-ID with a bolus and read (on average 6 test days per lactation) with a transceiver. According to the unitary prices on small scale in the EU during 2007 (bolus, €1.4; hand-held transceiver, €400; $\$ 1.89$ and $\$ 540$, respectively), an amortization period of $5 \mathrm{yr}$ and a minimum of 20,000 readings/yr ( $200 \mathrm{~d} \times 100$ goats/ d), the extra cost estimated for each milk recording in the e-ID goats was $€ 0.051 /$ goat ( $\$ 0.069 /$ goat). This cost value for an e-ID reading is in the range of the values previously reported by Saa et al. (2005) for sheep and goat in Spain.

The estimated e-ID extra cost ranged between $€ 1.22$ and $€ 24.48$ ( $\$ 1.65$ and $\$ 33.05$ ) for goat herds ranging 24 to 480 goats. The estimated saving of using the SA system ( $€ 0.50$ to $€ 12.9$ for 24 to 480 goats) did not compensate the extra cost of using e-ID, but repre- sented a contribution to the cost of implementing the e-ID of approximately $40 \%$. The other $60 \%$ should be due to other uses of the e-ID in the farm (i.e., automatic registration, kidding recording, health programs, traceability, automatic weighing).

Although the main advantage of using the SA instead of the $M$ system was the reduction in data transfer time, Caja et al. (1996) reported advantages in feasibility and reduction in number of operators needed for milk recording in dairy sheep, when e-ID boluses were read from the parlor pit (rear reading) vs. electronic ear tags read from the head lockers (front reading).

Results obtained in this experiment showed that the use of a SA milk recording system based on the use of electronic boluses had advantages in reading and transferring milking data in dairy goats. The SA system allowed the reduction of labor costs for milk recording and increased the accuracy of milk records, avoiding confusion and errors during data transfer. Advantages of the SA milk recording system would be greater for previously trained operators and for large goat herds. Ongoing innovations of automatic milk data collection (i.e., milk volume, milk flow rate) and software for dairy herd management may make the use of electronic identification more profitable in dairy goats in the future.

\section{ACKNOWLEDGMENTS}

This work is part of a research project funded by the Ministry of Education of Spain (Plan Nacional I+D+i; 
Project AGL-2007-64541) and was supported by a research scholarship to Adel Ait-Saidi from the International Centre for Advanced Mediterranean Agronomic Studies (Instituto Agronómico Mediterráneo de Zaragoza, Spain). The authors are grateful to Ramon Costa and the team of the S1GCE (Servei de Granges i Camps Experimentals) of the UAB for the care of the animals and to Nic Aldam for the English revision of the manuscript.

\section{REFERENCES}

Afimilk. 2007. Sheep \& Goat Management System. http://www. afimilk.com/SiteFiles/1/155/1045.asp Accessed Oct. 29, 2007.

Billon, P., and B. Baritaux. 1999. Milking parlours for large herds in France. Pages 201-208 in Milking and Milk Production of Dairy Sheep and Goats. F. Barillet and N. P. Zervas, ed. EAAP Publication No. 95. Wageningen Pers, Wageningen, the Netherlands.

Caja, G., F. Barillet, R. Nehring, C. Marie, O. Ribó, E. Ricard, G. Lagriffoul, C. Conill, M. R. Aurel, and M. Jacquin. 1996. Comparison of different devices for electronic identification in dairy sheep. Pages 349-353 in Performance Recording of Animals. J. Renaud and J. van Gelder, ed. EAAP Publication No. 87. Wageningen Pers, Wageningen, The Netherlands.

Caja, G., S. Peris, C. Conill, R. Nehring, R. Roca, O. Ribó, and M. J. Milán. 1999. Implementation of a system based on electronic identification for the official milk recording of dairy goats in Catalonia. Pages 406-411 in Milking and Milk Production of Dairy Sheep and Goats. F. Barillet and N. P. Zervas, ed. EAAP Publication No. 95. Wageningen Pers, Wageningen, the Netherlands.

Carné, S., G. Caja, J. J. Ghirardi, and A. A. K. Salama. 2007. Effects of age and rearing method on long-term retention of different electronic identification devices in goat. J. Anim. Sci. 85(Suppl. 1):93. (Abstr.)

DeLaval. 2007. Milk meters SG. http://www.delaval-us.com/Produc ts/Sheep_goat/MilkMeters/default.htm?wbc_purpose=BasicAb out_DeLa Accessed Oct. 29, 2007.

Fallon, R. J. 2001. The development and use of electronic ruminal boluses as a vehicle for bovine identification. Rev. Sci. Tech. Off. Int. Epizoot. 20:480-490.

Ghirardi, J. J., G. Caja, D. Garín, J. Casellas, and M. HernándezJover. 2006a. Evaluation of the retention of electronic identification boluses in the forestomachs of cattle. J. Anim. Sci. 84:2260-2268.
Ghirardi, J. J., G. Caja, D. Garín, M. Hernández-Jover, O. Ribó, and J. Casellas. 2006b. Retention of different sizes of electronic identification boluses in the forestomachs of sheep. J. Anim. Sci. 84:2865-2872.

ICAR (International Committee for Animal Recording). 2007. Subject: ICAR Recording Guidelines. http://www.icar.org/Documents/Rul es\%20and\%20regulations/Guidelines/Guidelines_2007.pdf Accessed Oct. 29, 2007.

Ilahi, H., P. Chastin, F. Bouvier, J. Arhainx, E. Ricard, and E. Manfredi. 1999. Milking characteristics of dairy goats. Small Rumin. Res. 34:97-102.

ISO (International Organization for Standardization). 1996. Radiofrequency identification of animals-Code structure. ISO 11784:1996 (E), 2nd ed. 1996-08-15, Geneva, Switzerland.

JRC (Joint Research Centre). 2007. IDEA Project, large scale project on livestock electronic identification. Final Report. v. 5.2. http:// idea.jrc.it/pages\%20idea/final\%20report.htm Accessed October 29, 2007.

MAPA (Ministerio de Agricultura. Pesca y Alimentación). 2007. Guías de prácticas correctas de hygiene. Caprino de carne y leche. http:// www.mapa.es/ganaderia/pags/practicas/CCAECAPRINO.pdf Accessed Oct. 29, 2007.

Peris, S., X. Such, and G. Caja. 1999. Machine milkability of Murciano-Granadina dairy goats. in Milking and Milk Production of Dairy Sheep and Goats. F. Barillet and N. P. Zervas, ed. EAAP Publication No. 95. Wageningen Pers, Wageningen, the Netherlands.

Pinna, W., P. Sedda, G. Moniello, and O. Ribó. 2006. Electronic identification of Sarda goats under extensive conditions in the island of Sardinia. Small Rumin. Res. 66:286-290.

Ricard, E., J. Arhainx, J. P. Guillouet, F. Bouvier, M. Jacquin, P. Chastin, J. M. Astruc, G. Lagriffoul, E. Manfredi, and F. Barillet. 1994. On-farm test of INRA portable electronic jars for automatized milk recording of sheep and goats. Pages 47-51 in Performance Recording of Animals. P. Gailon and Y. Chabert, ed. EAAP Publication No. 50. Wageningen Pudoc, Wageningen, the Netherlands.

Saa, C., M. J. Milán, G. Caja, and J. J. Ghirardi. 2005. Cost evaluation of the use of conventional and electronic identification and registration systems for the national sheep and goat populations in Spain. J. Anim. Sci. 83:1215-1225.

Salama, A. A. K., X. Such, G. Caja, M. Rovai, R. Casals, E. Albanell, M. P. Marin, and A. Martí. 2003. Effects of once versus twice daily milking throughout lactation on milk yield and milk composition in dairy goats. J. Dairy Sci. 86:1673-1680.

WestfaliaSurge. 2007. Equipos para cabras. http://www.westfalia. com/es/es/products_services/featuredinstallations/Goats/ default.aspx Accessed Oct. 29, 2007. 